\title{
RESILIENSI MAHASISWA PENERIMA BIDIK MISI
}

\author{
Amien Wahyudi dan Siti Partini \\ Program Studi Bimbingan dan Konseling Universitas Ahmad Dahlan \\ amien.wahyudi@bk.uad.ac.id
}

\begin{abstract}
Article Info
Available online

Penelitian ini bertujuan untuk mengetahui resiliensi mahasiswa penerima beasiswa bidik misi.

Metode yang digunakan dalam penelitian ini adalah metode penelitian kualitatif dengan pendekata

15.06.2019

studi kasus. Responden penelitian ini adalah mahasiswa penerima beasiswa bidik misi sebanyak dua mahasiswa yang memiliki kriteria 1) Mahasiswa penerima beasiswa bidik misi, 2) memiliki $\mathrm{IPK} \pm \geq 3,50,3)$ aktif dalam organisasi kemahasiswaan serta memiliki prestasi dalam bidang karya ilmiah. Pengumpulan data menggunakan wawancara terbuka, wawancara non formal dan observasi. Data yang didapat pada penelitian ini kemudian di deskriptifkan. Dari data deskriptif ini kemudian dilakukan analisis jawaban, yang selanjutnya dikodekan dan dilakukan identifikasi untuk mendapatkan tema-tema dalam dalam penelitian. Resiliensi mahasiwa penerima bidik misi dapat dilihat dari aspek meaningfullnes, preserverance, equanimity, self reliance, dan exsistential aloneness. Mahasiswa penerima bidik misi ternyata dapat melepaskan dirinya dari stresor ekonomi dan keluarga sehingga mahasiwa penerima bidik misi menjadi pribadi yang memiliki tujuan jelas dalam kehidupan.
\end{abstract}

Kata Kunci : Resiliensi dan Mahasiswa

\begin{abstract}
:
The purpose of this study is to know the resiliency of scholarship recipients. The method used in this research is a qualitative research method with a short case study. The respondents of this study are scholarship recipients of two students who have the criteria 1) Scholarship recipients, 2) have a GPA of $\pm \geq 3,50,3$ ) active in student organizations and have achievements in the field of scientific work. Data collection uses open interviews, non-formal interviews and observations. Data obtained in this research is then descriptive. From this descriptive data then the answer analysis, which is then encoded and identifiable to get the themes in the research. The resilience of missionary viewers can be seen from the aspects of meaningfullness, preserverance, equanimity, self reliance, and exsistential aloneness. The recipient of the missionary course is able to relinquish himself from economic and family tutoring so that the recipient of missionary vision becomes person who has a clear purpose in life.
\end{abstract}

\section{PENDAHULUAN}

Bidik misi merupakan bantuan biaya pendidikan bagi calon mahasiswa yang mengalami masalah ekonomi tetapi memiliki potensi akademik yang baik sehingga mampu untuk menempuh pendidikan di perguruan Tinggi. Dengan adanya beasiswa bidik misi, perguruan tinggi yang selama ini terkesan sulit di masuki oleh mahasiswa yang memiliki masalah ekonomi menjadi tidak relevan lagi di masa depan. Resiliensi sendiri didefinisikan sebagai "defines resilience as the "self-righting tendencies" of the person, "both the capacity to be bent without breaking and the capacity, once bent, to spring back”" (Adrian Du Plessis Van Breda, 2001). Definisi ini menunjukan bahwa yang namanya resiliensi merupakan kapasitas individu untuk terus berusaha dan bangkit dari masalah yang dihadapinya dan menjadi baik tanpa harus melanggar aturan yang berlaku. 
Pendapat di atas dapat dimaknai bahwa resiliensi merupakan keterampilan, kemampuan, pengetahuan, dan wawasan yang di dapat dari waktu ke waktu sebagai orang berusaha untuk mengatasi kesulitan dan menghadapi tantangan yang dimasa depan. Maka dari pendapat di atas dapat disimpulkan bahwa mahasiswa penerima bidik misi merupakan individu yang idealnya memiliki kemampuan beradaptasi, bertahan, bahkan harus mampu bangkit dalam menghadapi kesulitan yang akan dihadapi oleh penerima bidik misi tersebut. Beberapa penelitian tentang resiliensi telah dilakukan, misal penelitian resiliensi yang dilakukan oleh Anita Novianty (2011) yang meneliti tentang penyesuaian dusun jangka panjang ditinjau dari resiliensi komunitas pasca gempa, penelitian ini menemukan korelasi positif antara resiliensi komunitas di suatu wilayah dengan tingkat kedamaian penduduk yang tinggal di daerah tersebut. Kehidupan manusia tidak dapat dilepaskan dari masalah. Masalah yang terjadi pada manusia bila dilihat dalam kacamata agama islam merujuk kepada beberapa hal, Sutoyo (2009) menuliskan bahwa

"apabila masalah tersebut menimpa orang yang beriman maka masalah tersebut boleh jadi sebuah ujian, apabila masalah tersebut menimpa orang biasa boleh jadi sebagai pengingat agar segera kembali kejalan yang telah ditentukan oleh Allah SWT, tetapi apabila masalah itu terjadi pada manusia yang senantiasa berbuat kerusakan boleh jadi masalah tersebut merupakan balasan oleh Allah SWT”. Allah SWT telah berfirman :

Dan sungguh akan Kami berikan ujian kepada mu dengan sedikit ketakutan, kelaparan, kekurangan harta, Jiwa dan buah-buahan. Dan berikanlah kegiembiraan kepada orang-orang yang sabar (Al baqoroh 155)

Bila merujuk kepada ayat ini maka kekurangan harta yang dialami oleh mahasiswa penerima bidik misi merupakan sebuah ujian, dan apabila mahasiswa penerima bidik misi itu bersabar atas kondisi yang terjadi maka ada kabar gembira yang diberikan untuk individu yang bersabar tersebut. Untuk mahasiswa penerima bidik misi berdasarkan wawancara awal peneliti dengan beberapa mahasiswa penerima bidik misi, diketahui bahwa latar belakang keluarga penerima bidik misi berasal dari golongan menengah kebawah dengan jenis pekerjaan yang dilakukan oleh orang tua, seperti buruh tani, pedagang di pasar, penjual jamu dan pedagang makanan kecil. Kondisi ekonomi seperti ini tentu saja membuat mahasiswa penerima bidik misi membutuhkan usaha yang keras untuk sekolah sampai pada jenjang pendidikan tinggi. Bahkan untuk meringankan beban rang tua, mahasiswa yang menerima bidik misi ini, tidak jarang bekerja paruh waktu untuk meringankan beban ekonomi orang 
tua. Tetapi walaupun demikian prestasi yang diraih mahasiswa bidik misi tidak kalah dengan mahasiswa lainnya, hal ini dapat dilihat dari nilai IPK mahasiswa yang mencapai angka $\pm \geq 3,50$

\section{Gmbaran Resiliensi Responden}

\section{Meaningfullnes}

Meaningfullnes merupakan kesadaran bahwa hidup memiliki tujuan dan diperlukan usaha untuk mencapai tujuan tersebut. Dari wawancara yang dilaksankan terhadap responden Y tujuan individu untuk masa depan adalah menjadikan keluarga sebagai prioritas. Ini dapat di pahami mengingat selama ini peranan keluarga terutama ibu dan kakak sangat dominan dalam membantu usaha individu untuk berkembang. Guna mencapai tujuan untuk membuat keluraga lebih mapan dan bahagia, responden telah menentukan dan merumuskan tujuan masa depan yaitu dengan cara belajar dan berusaha seoptimal mungkin. Responden memiliki padangan positif sebagai motivasi internal bagi dirinya. Responden memiliki pandangan bahwa bila orang lain mampu maka respondenpun mampu melaksankannya. Pandangan positif ini dapat memberikan motivasi internal yang baik bagi individu. Pandangan ini juga membuat individu mampu untuk berkembang menjadi lebih baik dan terus berusaha mengembangkan potensi yang dimiliki guna mendukung cita-vita responden di masa depan. Untuk responden $X$ tujuan hidup dari responden saat ini adalah segera menyelesaikan studi yang sedang dijalani dengan optimal. Usaha yang dilakukan oleh individu adalah mengikuti materi yang masih tersisa agar dapat menyelesaikan segera studinya. Saat ini responden memiliki IPK 3,8. Usaha optimal dilakukan merupakan bentuk tanggungjawab responden terhadap kesempatan melanjutkan studi di perguruan tinggi yang didapatkan responden melalui beasiswa bidik misi

\section{Preserverance}

Preserverance merupakan sikap individu yang dapat bertahan dalam menghadapi kesulitan hidup. Setidaknya sebagai mahasiswa penerima bidik misi, responden Y memiliki keterbatasan dalam mencapai tujuan hidup yaitu keterbatasan dalam pendanaan dan waktu. Responden memiliki sikap yang positif dan empati terhadap kegagalan individu lainya dan menjadikan kegagalan individu tersebut sebagai bahan pelajaran bagi diri responden, perasaan sedih melihat kegagalan orang lain, apalagi orang tersebut dikenal responden bisa disebabkan pengalaman hidup responden yang berada dalam situasi yang tidak ideal saat ini. Untuk reaksi responden melihat keberhsilan orang lain dapat dipahami dari kata-kata responden saat wawancara yang menyatakan bahwa responden senang dengan keberhasilan orang lain dan bagi diri responden saat ini yang terpenting adalah membahagiakan orang tua. Responden $\mathrm{X}$, dalam kehidupan responden saat ini yang paling penting 
adalah menjalin hubungan dengan orang lain keluarga dan membangun relasi. Sebagai makhluk sosial maka sangat wajar responden memiliki keinginan membangun komunikasi dengan baik. Responden merupakan orang yang mudah bergaul dan memiliki kemampuan komunikasi yang baik. Hambatan yang dihadapi responden dalam menyelesaikan tujuan hidup atau studi lebih kepada padatnya agenda sebagai mahasiswa bidik misi dalam amatan peneliti responden sering pulang malam dari kampus karena responden memiliki tugas tambahan untuk menjaga laboratorium konseling. Selama menjalani studi, responden $\mathrm{X}$ sejak sekolah dasar hingga perguruan tinggi selalu mendapatkan beasiswa atau keringanan dalam menjalankan studi, ini menunjukan bahwa responden memiliki kemampuan akademik yang baik.

\section{Equanimity}

Equanimity merupakan suatu persfektif tentang keseimbangan dalam menjalani kehidupan. Tentang keseimbangan responden $\mathrm{Y}$ dapat dilihat dari pandangan responden terhadap kondisi ekonomi keluarga saat ini dimanan keadaan ekonomi menjadi tekanan tersendiri sehingga untuk mengatasi permasalaha ekonomi tersebut membuat responden banyak beristiqfar dan berpandangan positif dengan cara mengagap bahwa masalah yang terjadi merupakan cara untuk mendapatkan rezeki yang lain. Menghadapi permasalahan ekonomi membuat responden berusaha semakin mendekatkan diri kepada Allah SWT. Dengan banyak mengingat Allah maka perasaan akan menjadi tenang dan pandangan bahwa rezeki bisa didapatkan dari usaha yang baik pula. Menerima takdir dan meyakini masa depan merupakan pandangan positif individu. Pandangan positif seperti ini dapat membuat individu berusaha menjalani kehidupan sebaik-baiknya. Selain itu keinginan untuk mencapai masa depan yang lebih baik menjadi motivasi tersendiri bagi responden.

Untuk respoden $\mathrm{X}$, keseimbangan ini dapat terlihat dari penerimaan individu terhadap kehidupan yang sedang dijalani saat ini, terutama dalam melihat kondisi ekonomi yang kurang baik sejak lama membuat responden merasa bersyukur. Keseimbangan ini adalah penerimaan responden yang dapat menjadikan responden lebih tenang dalam menjalani kehidupan. Tidak jarang individu yang tidak memiliki keseimbangan dalam hidup dapat mengalami masalah dalam perjalanan kehidupannya. Ada individu-individu yang tidak dapat menerima kondisi ekonomi yang sulit sehingga berbuat hal-hal yang melanggar hukum tetapi ini tidak dilakukan oleh responden karena responden memandang bahwa hidup dalam kesederhaan adalah suatu cara untuk mencapai ketenangan dalam kehidupan

\section{Self reliance}


Self reliance merupakan keyakinan pada diri sendiri dan kapasitas diri. Pada bagian ini responden Y memandang bahwa responden memiliki sifat negatif. Sifat negatif ini muncul pada saat-saat tertentu seperti kurang bisa mengontrol emosi saat kondisi letih. Sifat yang dikemukakan di ini masih wajar muncul dalam diri individu. Apalagi bila individu tersebut berada dalam kondisi fisik yang kurang baik. Emosi individu juga dipengaruh oleh kondisi fisik apalagi responden adalah wanita yang masih dalam usia remaja yang sangat mungkin memiliki kelabilan emosi seperti remaja pada umumnya. Responden memandang bahwa apa yang disampaikan oleh orang lain terhadap responden ternyata tepat. Pandangan orang lain penting untuk digunakan menilai diri sendiri, karena manusia hidup dalam dinamika sosial yang tidak dapat dipisahkan dengan individu lainnya. Untuk responden $\mathrm{X}$ berdasarkan wawancara, responden X merupakan individu yang memiliki kapasitas yang baik dalam artian tidak banyak masalah yang ditimbulkan responden dalam lingkungan pergaulan dan di lingkungan masyarakat tempat responden tinggal saat ini. Selain itu responden memiliki keyakinan bahwa apa yang ingin dicapai dimasa depan dapat tercapai bila responden selalu menjaga motovasi dan semangat dalam berusaha

\section{Exsistential alones}

Exsistensial alones merupakan kesadaran bahwa perjalanan setiap individu itu unik. Untuk responden Y, kesadaran tersebut dapat digambarkan melalui sikap yang dapat berbeda dengan yang lainnya dalam memandang berbagai macam permasalahan Pada bagian ini responden $\mathrm{X}$ memiliki kemampuan dalam berbeda pendapat dengan individu lain, tetapi cara mengemukakan perbedaan itu tidak secara langsung dikemukakan didalam forum yang sedang diikuti karena ada rasa sungkan bagi individu untuk mengungkapkan perbedaan di depan forum. Hal ini dapat dipahami sebagai cara individu untuk tidak melakukan konfrontasi terbuka terhadap perbedaan yang terjadi di dalam forum diskusi atau rapat yang sedang diikuti. Keunikan individu ini dapat dipahami bahwa sebagai remaja jawa nilai-nilai rukun sangat ditanamkan dalam kehidupan. Perbedaan yang terjadi dalam sebuah forum diskusi sangat mungkin terjadi tetapi perbedaan itu hendaknya dikelola dengan baik agar tidak terjadi permusuhan di dalam menjalankan aktivitas lainnya bagi responden.

\section{PEMBAHASAN}

Resiliensi merupakan sebuah kajian yang membahas tentang kemampuan individu untuk bangkit saat menghadapi masalah yang sedang menimpa diri individu tersebut. Resiliensi adalah ciri kepribadian yang bersifat stabil ditandai oleh kemampuan individu untuk bangkit kembali dari 
pengalaman negatif dan kemampuan menyesuaikan diri terhadap perubahan kehidupan yang terusmenerus (Connor, 2006; Everal, Altrows dan Paulson., 2006; Frederikson dkk, 2003). Penelitian ini berfokus kepada resiliensi mahasiswa penerima bidik misi. Penelitian resiliensi mahasiswa penerima bidik misi dipengaruhi oleh beberapa faktor diantaranya adalah keluarga, religiulitas, kebermaknaan hidup dan tujuan hidup individu, media masa dan teman sebaya, hal ini sejalan dengan hasil penelitian dari Bonano,dkk (2007) dalam penelitiannya menemukan bahwa faktor yang mempengaruhi resiliensi diantaranya adalah jenis kelamin, usia, ras, pendidikan, tingkat trauma, pendapatan, dukungan sosial, frekuensi penyakit kronis, tekanan kehidupan masa lalu dan sekarang.

Faktor lainnya yang berkontribusi terhadap perkembangan resiliensi indvidu adalah self efficacy. Gist dan Mitchell (dalam Ghufron dan Rini, 2010; Atika,2015) mengatakan bahwa self-efficacy dapat membawa pada perilaku yang berbeda di antara individu dengan kemampuan yang sama karena selfefficacy mempengaruhi pilihan, tujuan, pengetasan masalah, dan kegigihan dalam berusaha. Bila dilihat dari pandangan ini kemampuan individu dan kegigihan individu dalam berusaha dan mengatasi permasalahannya sangat erat kaitannya dengan kemampuan self efficacy individu. Selain self efficacy faktor lain yang tidak kalah penting dalam mendukung reiliensi individu adalah jaringan keluarga atau dukungan keluarga (Black,K. and Lobo.M,2008;Anstasi.B,2017). Pada penelitian ini dukungan keluarga sangat besar memberikan kontribusi bagi perkembangan resiliensi individu, kebanyakan dukungan keluarga yang diberikan berupa motivasi agar individu dapat lebih bisa berkembang, faktor keluarga yang memberikan dukungan sosial dapat membetuk mahasiswa penerima bidik misi memiliki kesehatan emosional sosial yang baik yang pada akhirnya kesehatan emosional sosial ini memberikan pengaruh positif terhadap prestasi akademik individu (Yansaputri dan Wijaya,2017). Resiliensi responden penelitian pada penelitian ini juga dapat dilihat dari pendapat Wagnil (2009) yang memandang bahwa terdapat lima karakteristik resiliensi individu yaitu: meaningfullnes, preserverance, equanimity, self reliance, dan exsistential aloneness. Lebih lanjut Jenifer R.Riley dan Ann S Masten (dalam Ray Dev,Bonnie dan Robert,2005) mengemukakan bahwa risiliensi

"mengacu pada pola adaptasi individu yang positif dalam menghadapi permasalahan yang terjadi, setidaknya ada dua kondisi untuk mengambarkan ketahanan individu dalam beradaftasi tersebut yaitu a) kesiapan individu dalam beradaptasi terhadap permasalah yang telah terjadi dan b) kemampuan individu untuk terus berfungsi sebagai manusia dalam menghadapi masalah tersebut".

Keberfungsian individu sangat penting saat menghadapi masalah, individu yang berfungsi dengan baik akan cepat menyesuaikan diri dengan masalah yang sedang dihadapi, optimisme untuk dapat 
bertahan saat menghadapi masalah menjadi keharusan karena sesungguhnya Allah SWT telah berfirman "Maka sesungguhnya bersama kesulitan ada kemudahan” (Asy Syarh, 5). Pengalaman hidup responden penelitian yang berada dalam kondisi ekonomi yang tidak ideal telah menjadikan responden sebagai individu yang tangguh dalam menjalani kehidupan. Pandangan positif responden terhadap permasalah ekonomi yang terjadi menjadikan responden penelitian telah menentukan tujuan dari kehidupannya dan tidak dapat dipungkiri bahwa dukungan keluarga berperan penting bagi terbentuknya resiliensi individu.

\section{KESIMPULAN}

Bahwa resiliensi individu ditentukan oleh banyak faktor. Faktor yang cukup dominan yang mendukung resiliensi individu pada penelitian ini adalah faktor keluarga. Kesadaran dan penerimaan diri terhadap kondisi ekonomi keluarga, mampu membuat individu berpikir realistis dal am menjalani kehidupan sebagai mahasiswa. Selain itu motto dalam kehidupan responden $\mathrm{Y}$ dan X yang memandang "apabila orang lain mampu maka akupun maтрu” mendorong individu untuk berusaha optimal dalam menjalankan peranannya sebagai mahasiswa.

\section{DAFTAR RUJUKAN}

Adrian Du Plessis Van Breda.2001. Riselence Theory: A Literature Review. Pretoria, South Africa: South African Military Health Service, Military Psychological Institute, Social Work Research \& Development

Anastasia,B.,Iro Mylonakou,K.,Orania,K.,and Nikolaos,T.2017.Primary School Teachers' Resilience During The Economic Crisis In Greece.Journal Psycology vol 8

Anita Novianty.2011. Penyesuaian dusun jangka panjang ditinjau dari resiliensi komunitas pasca gempa. Jurnal Psikologi. Volume 38. No 1. Juni 2011. Hal 30-39

Anwar Sutoyo.2009.Bimbingan dan Konseling Islami.Widya Karya.Semarang

Black,K and Lobo,M.2008.A Conceptual review of family resilience factors.Journal of Family Nursing vol 14 pp 33-55

Bonano, G.A., Galea, S., Bucciarelli, A., and Vlahov, D.2007. What psycho-logica resilience after disaster? The role of demographics, resources and life stress. Journal of Counsulting and Clinical Psychology vol 75 pp 671- 682.

Connor, M.K.2006. Assesment of resilience in the aftermath trauma. Journal of Clinical

Everal, D.R., Altrows, J.K., and Paulson, L.B.2006. Creating a future: A study of resilience in suicidal female adolescents. Journal of Counseling and Development vol 84 pp 461-470. 
Frederickson, L.B., Tugade, M.M., Waugh, E.C., and Larkin, R.G. 2003. What good are positive emotion in crisis? A prospective study of resilience and emotion following the terorrist attacks on the United States on September 11th, 2001. Journal of Personality and Social Psychology vol 84 pp 365- 376.

Nurul, Atieka. 2015. Self Efficacy Of Orphanage Adolescent And Improved Through With Group Counseling Approach. Guidena Journal of Guidance and Counseling. Volume 5. No 2. December. 2015

Ray Dev, Bonnie dan Robert.2005. Resilience in Children,Families, and Comunities.Plenum Plublisher.New York

Wagnild, Gaild (2009).A Review of The Resilience Scale. Journal Of Nursing Measurmen, 17 (2)

Yansaputri Intan Shabrina,Wijaya Hariz Enggar. The Role of Social Emotional Helat on Academic Achievement of College Studens. Guidena Journal of Guidance and Counseling. Vol 7 Nomor 1 Juni 2017 